\title{
Budget impact analysis of biosimilar infliximab (CT-P13) for the treatment of rheumatoid arthritis in six Central and Eastern European countries
}

\author{
Valentin Brodszky · Petra Baji · Orsolya Balogh • \\ Márta Péntek
}

Received: 17 February 2014 / Accepted: 31 March 2014/Published online: 16 May 2014

(C) Springer-Verlag Berlin Heidelberg 2014

\begin{abstract}
The first biosimilar monoclonal antibody (infliximab, CT-P13) was registered by the European Medicines Agency in 2013 for the treatment of several inflammatory conditions including rheumatoid arthritis (RA). Biosimilar infliximab is first being marketed in the Central and Eastern European countries. This paper presents the estimated budget impact of the introduction of biosimilar infliximab in RA over a 3-year time period in six selected countries, namely Bulgaria, the Czech Republic, Hungary, Poland, Romania and Slovakia. A prevalencebased model was constructed for budget impact analysis. Two scenarios were compared to the reference scenario (RSc) where no biosimilar infliximab is available: biosimilar scenario 1 ( $\mathrm{BSc} 1)$, where interchanging the originator infliximab with biosimilar infliximab is disallowed, and only patients who start new biological therapy are allowed to use biosimilar infliximab; as well as biosimilar scenario 2 (BSc2), where interchanging the originator infliximab with biosimilar infliximab is allowed, and $80 \%$ of patients treated with originator infliximab are interchanged to biosimilar infliximab. Compared to the RSc, the net savings are estimated to be $€ 15.3$ or $€ 20.8 \mathrm{M}$ in BSc1 and $\mathrm{BSc} 2$, respectively, over the 3 years. If budget savings were spent on reimbursement of additional biosimilar infliximab treatment, approximately 1,200 or 1,800 more patients could be treated in the six countries within 3 years in the two biosimilar scenarios, respectively. The actual
\end{abstract}

\footnotetext{
V. Brodszky $(\bowtie) \cdot$ P. Baji · O. Balogh · M. Péntek Department of Health Economics, Corvinus University of Budapest, Fővám tér 8, Budapest 1093, Hungary e-mail: valentin.brodszky@uni-corvinus.hu

M. Péntek

Department of Rheumatology, Flór Ferenc County Hospital, Semmelweis tér 1, Kistarcsa 2143, Hungary
}

saving is most sensitive to the assumption of the acquisition cost of the biosimilar drug and to the initial number of patients treated with biological therapy. The study focused on one indication (RA) and demonstrated that the introduction of biosimilar infliximab can lead to substantial budget savings in health care budgets. Further savings are expected for other indications where biosimilar medicines are implemented.

Keywords Budget impact analysis - Biosimilar pharmaceuticals · Rheumatoid arthritis · Central and Eastern Europe

JEL Classification I110 Analysis of Health Care Markets

\section{Introduction}

Chronic inflammatory conditions, such as different types of autoimmune arthritis, inflammatory bowel diseases and psoriasis, lead to considerable functional disability, a lowered quality of life and work capacity, as well as significant economic burden on the patients, families and society. Biological drugs developed over the recent decades provided new, highly effective, but very costly treatment options [1]. The high price created a barrier to access for patients in the Central and Eastern European (CEE) region, and the utilization of biological drugs is still lower compared to high income countries [2]. Access to biological drugs varies greatly within the CEE as well.

In September 2013, a biosimilar monoclonal antibody (mAb), infliximab (CT-P13) received market authorisation in Europe for the treatment of adult patients with rheumatoid arthritis (RA), ankylosing spondylitis, 
psoriatic arthritis, psoriasis, adult and pediatric ulcerative colitis, and Crohn's disease. It is expected that the spread of biosimilar mAbs will lead to cost savings in health care budgets, and might also improve the access to biological therapies. However, the potential savings have not yet been studied. This study aimed to analyse the budget impact implied by the introduction of biosimilar infliximab for the treatment of RA in six selected CEE countries, namely Bulgaria, Czech Republic, Hungary, Poland, Romania and Slovakia. RA was selected to estimate the budget impact, as this indication involves the largest number of patients treated with biological agents.

Budget impact analysis (BIA) is used to estimate the financial consequences of adoption and diffusion of a new health intervention within a specific health care setting or system context [3-5]. Besides cost-effectiveness analysis (CEA), BIA is required as part of the application dossiers of all new pharmaceuticals seeking public funding in the $\mathrm{CEE}$, similar to a number of other countries. However, despite the importance of BIA, there is a shortage of literature in this field compared to the large number of CEAs. In a systematic literature review by Orlewska et al. [4], altogether 34 BIAs were identified in peer-reviewed journals, irrespective of therapy type and geographical region. In a recent systematic literature review by van de Vooren et al. [5], 17 BIA publications focusing on European countries were identified. Furthermore, both reviews pointed out that several studies fail to reach appropriate methodological quality. Amongst the publications included in these reviews, only two BIAs dealt with biological treatments, both in RA $[6,7]$ and none of these studies was conducted in the CEE region. No studies that focus on the expected budget impact of biosimilar drugs have been published so far.

It is rather challenging to estimate the budget impact of a new biosimilar $\mathrm{mAb}$ drug in the CEE region for several reasons. First, data on current, available biological treatments (price and patient populations, practice of current biological use) are not always available or reliable for all CEE countries. Patient registries are scarce in CEE; thus our knowledge is limited regarding size, disease severity and other characteristics of patients currently using biological drugs, as well as the pattern of biological treatment in this region. Second, we have to rely on assumptions regarding the future use of a biosimilar drug (market share, interchanging or switching of biological therapies).

Thus, in this paper we estimated cost savings from the payer's perspective in six CEE countries, considering two extreme biosimilar scenarios (BScs), depending on whether interchanging a biosimilar is allowed or not, compared to the reference scenario (RSc) where no biosimilar infliximab is available.

\section{Methods}

This BIA estimated the impact of biosimilar infliximab on the healthcare budget over a 3-year time frame in six CEE countries. The model was constructed in compliance with the principles of good practice for BIA from the International Society for Pharmacoeconomics and Outcomes Research (ISPOR) [3]. The perspective of analysis was that of a third party payer.

\section{Modelling framework}

A prevalence-based, country-specific budget impact model was developed for RA. The budget impact model evaluated the impact of introducing biosimilar infliximab into the current treatment mix of biological drugs available for the treatment of RA in the six countries by comparing total costs (drug, administration and monitoring) of scenarios where biosimilar infliximab is introduced (BSc1 and BSc2) to the total costs of the RSc (where no biosimilar agent is available). Since there is a great uncertainty in policy discussions around interchanging originator infliximab with biosimilar infliximab (see the paper of Tóthfalusi et al. [8] in this supplement) we decided to explore the budget impact in two extreme scenarios:

Biosimilar scenario 1 ( $B S C l)$ Interchanging originator infliximab with biosimilar infliximab is disallowed. Only patients who start a new biological therapy are allowed to use biosimilar infliximab.

Biosimilar scenario 2 (BSc2) Interchanging of originator infliximab with biosimilar infliximab is allowed after 6 months from treatment start, and originator infliximab is interchanged by biosimilar infliximab in $80 \%$ of patients. Also patients who start a new biological therapy are allowed to receive biosimilar infliximab as first-line therapy.

The model tracked the movement of patients between different biological treatments. At the end of each model cycle, patients could either remain on the original treatment, or switch to another biological treatment, or leave the model (switch to a conventional synthetic disease modifying antirheumatic drug [csDMARD] therapy). The model functioned in quarter-year time cycles according to a 3-month-long evaluation period. The number of RA patients treated with biological agents in any quarter year was the sum of the population in the previous quarter year and the estimated growth. The number of patients starting new biologic treatment (first drug or switch) was the sum of discontinuations from all causes in the previous quarter year and the estimated growth. New patients receiving biological drugs exactly compensated for patients exiting the model. 
Total costs of scenarios were estimated as the aggregation of the product of patients in different model states and costs associated with these states. Incremental costs were calculated as the difference of BScs (BSc1 and BSc2) and RSc. Cost savings are reported in 2013 prices; no discounting was applied. Besides cost savings in monetary terms, we also provide estimations for gains in terms of possible number of new patients who could be treated additionally if the savings were reinvested in additional biosimilar infliximab treatment.

\section{Patient population}

The size of initial populations (Table 1) in both the reference (RSc) and the two BScs (BSc1 and Bsc2) were set on the basis of real 2013 penetration data in the six CEE countries (i.e. the number of patients with RA treated with different biological drugs in 2013). The number of RA patients in the six countries treated with abatacept, adalimumab, certolizumab, etanercept, golimumab, infliximab, rituximab and tocilizumab were $153,4,055,1,376,4,197,860,1,643,3,098$ and 1,944, respectively [9]. The model also accounted for the possibility of patient number expansion. A future growth rate of treated patients was assumed to predict the number of treated patients over the 3 years. Also, budget impact estimates included calculations on the numbers of previously untreated patients who started new biological drugs. We made no restriction on the number of potential patients. We only assumed that growth in the number of patients treated with biological drug would not exceed the number of patients eligible for biological therapy on a 3-year time horizon.

\section{Costs associated with model states}

Only direct costs of the drug treatment were considered, including the acquisition costs of drugs, the cost of administration and the cost of treatment-related monitoring (laboratory test, rheumatology visits, X-ray, cardiology and pulmonology monitoring). The model accounted for those biological agents that are reimbursed in a given country for the treatment of RA (Table 2).

Drug acquisition costs were derived from official national price lists in each country. We used retail prices for the analysis. Retail price of biosimilar infliximab was assumed as $75 \%$ of originator infliximab in all six countries. Drug acquisition costs were calculated on a quarterly basis for both the induction and maintenance periods for each drug (Table 3). The doses and administration schedules for each biological agent were those provided by the European Medicines Agency summaries of product characteristics. The calculation took into account both induction and maintenance dosing schedule in the case of infliximab, certolizumab and abatacept. For these drugs,
Table 1 Model parameters

\begin{tabular}{|c|c|c|}
\hline Variables & $\begin{array}{l}\text { Base case } \\
\text { parameters }\end{array}$ & Source \\
\hline Average body weight in RA (kg) & 75 & $\begin{array}{c}\text { NHIFA } \\
2010\end{array}$ \\
\hline Initial population on biologic in RA & 17,257 & $\begin{array}{l}\text { Péntek et al. } \\
\text { [9] }\end{array}$ \\
\hline $\begin{array}{l}\text { Three months discontinuation } \\
\text { probability after } 6 \text { months }\end{array}$ & 0.049 & $\begin{array}{l}\text { Literature } \\
\text { review } \\
{[11]}\end{array}$ \\
\hline Biologic market yearly growth rate & $10 \%$ & Assumption \\
\hline $\begin{array}{l}\text { Biosimilar infliximab price in } \% \text { of } \\
\text { originator infliximab price }\end{array}$ & $75 \%$ & Assumption \\
\hline \multicolumn{3}{|c|}{ Distribution of switches from TNF-inhibitor to } \\
\hline Another TNF inhibitor & $60 \%$ & $\begin{array}{l}\text { NHIFA } \\
2013[12]\end{array}$ \\
\hline Abatacept & $0 \%$ & $\begin{array}{l}\text { NHIFA } \\
2013[12]\end{array}$ \\
\hline Rituximab & $7 \%$ & $\begin{array}{l}\text { NHIFA } \\
2013[12]\end{array}$ \\
\hline Tocilizumab & $33 \%$ & $\begin{array}{l}\text { NHIFA } \\
2013[12]\end{array}$ \\
\hline \multicolumn{3}{|c|}{ Distribution of switches from tocilizumab to } \\
\hline Another TNF inhibitor & $89 \%$ & $\begin{array}{l}\text { NHIFA } \\
2013[12]\end{array}$ \\
\hline Rituximab & $10 \%$ & $\begin{array}{l}\text { NHIFA } \\
2013[12]\end{array}$ \\
\hline \multicolumn{3}{|c|}{ Probability of switches from rituximab to } \\
\hline Another TNF inhibitor & 0.64 & $\begin{array}{l}\text { NHIFA } \\
2013[12]\end{array}$ \\
\hline Tocilizumab & 0.36 & $\begin{array}{l}\text { NHIFA } \\
2013[12]\end{array}$ \\
\hline $\begin{array}{l}\text { Rate of interchanging by the } \\
\text { physicians* }\end{array}$ & $0-80 \%$ & Assumption \\
\hline $\begin{array}{l}\text { Probability of initiating biosimilar } \\
\text { infliximab instead of starting } \\
\text { originator infliximab }\end{array}$ & $65 \%$ & Assumption \\
\hline $\begin{array}{l}\text { Probability of initiating biosimilar } \\
\text { infliximab instead of starting non- } \\
\text { infliximab TNF-inhibitor }\end{array}$ & $20 \%$ & Assumption \\
\hline
\end{tabular}

*Interchanging rate: the given rate is reached at the end of the first year applying a linear growth

NHIFA National Health Insurance Fund Administration

different dosing schedules were used in the first and the subsequent quarter after starting the treatment. Furthermore, the dosage of some biological drugs (infliximab, abatacept and tocilizumab) depends on body weight. The average body weight of an RA patient was estimated at $75 \mathrm{~kg}$ (SD17), based on Hungarian survey among patients treated with infliximab [10]. If a full package is not used for one patient, the rest of the dosage might or might not be used for others. The latter is considered as waste. We assumed that the rest of a dosages was administered to the next patient. 
Table 2 Retail prices of biological treatments in $€$

\begin{tabular}{|c|c|c|c|c|c|c|c|}
\hline \multirow[t]{2}{*}{ Brand name } & \multirow[t]{2}{*}{ Substance } & \multicolumn{6}{|c|}{ Retail price (EUR) } \\
\hline & & BUL & $\mathrm{CZE}$ & HUN & POL & $\mathrm{ROM}$ & SLO \\
\hline ORENCIA $1 \times 250$ & Abatacept & NR & 420 & 342 & NR & 352 & 395 \\
\hline HUMIRA $2 \times 40$ & Adalimumab & 1,262 & 1,006 & 957 & 1,056 & 1,037 & 1,119 \\
\hline CIMZIA $2 \times 200$ & Certolizumab & 1,093 & 975 & 957 & NR & 931 & 1,043 \\
\hline ENBREL $4 \times 50$ & Etanercept & 1,164 & 1,021 & 957 & 1,015 & 968 & 1,048 \\
\hline SIMPONI $1 \times 50$ & Golimumab & 1,282 & 1,112 & 1,109 & NR & 1,067 & 1,646 \\
\hline REMICADE $1 \times 100$ & Infliximab & NR & 609 & 534 & 537 & 481 & 617 \\
\hline MABTHERA $1 \times 500$ & Rituximab & 1,255 & 1,275 & 1,257 & 1,553 & 1,309 & 1,406 \\
\hline ROACTEMRA 400 & Tocilizumab & 1,255 & 846 & 728 & NR & 745 & 778 \\
\hline ROACTEMRA 200 & Tocilizumab & 948 & 423 & 366 & NR & 380 & 411 \\
\hline ROACTEMRA 80 & Tocilizumab & 479 & 169 & 148 & NR & 161 & 167 \\
\hline
\end{tabular}

Sources: SLO: http://www.adcc.sk; BUL: National Health Insaurance Fund, Списьк с лекарства, които НЗОК заплашапореданаНаредба № 10 от 24 март 2009г. заусловията и редазазаплапаненалекарственипродуктипочл. 262, ал.4, т.1 отЗаконазалекарственитепродукти в httр:// www.nhif.bg; CZE: State Institute for Drug Control, http://www.sukl.eu/; HUN: National Health Insaurance Fund www.oep.hu; POL: Ministry of Health, http://www.mz.gov.pl/; ROM: Ministry of Health, http://www.msf-dgf.roCatalogul National al preturil or medicamentel or de uzumanautorizate de punerepepiata-Ianuarie 2012

NR not reimbursed, BUL Bulgaria, CZE Czech Republic, HUN Hungary, POL Poland, ROM Romania, SLO Slovakia

Table 3 Quarterly drug costs in rheumatoid arthritis, in euros

$Q$ quarter year, Inf original infliximab, $A d l$ adalimumab, $C r t$ certolizumab, Etn etanercept, Glm golimumab, Abt abatacept, Rtx rituximab, $T c l$ tocilizumab

\begin{tabular}{|c|c|c|c|c|c|c|c|c|c|c|c|}
\hline \multirow[t]{2}{*}{ Country } & \multicolumn{2}{|l|}{ Inf } & \multicolumn{2}{|l|}{ Adl } & \multicolumn{2}{|l|}{$\mathrm{Crt}$} & \multirow{2}{*}{$\begin{array}{l}\text { Etn } \\
Q_{\text {i }}\end{array}$} & \multirow{2}{*}{$\begin{array}{l}\text { Glm } \\
Q_{\mathrm{i}}\end{array}$} & \multirow{2}{*}{$\begin{array}{l}\text { Abt } \\
Q_{\mathrm{i}}\end{array}$} & \multirow{2}{*}{$\begin{array}{l}\text { Rtx } \\
Q_{\mathrm{i}}\end{array}$} & \multirow{2}{*}{$\begin{array}{l}\text { Tcl } \\
Q_{\mathrm{i}}\end{array}$} \\
\hline & $Q 1$ & $Q 2$ & $Q_{\mathrm{i}}$ & $Q_{\mathrm{i}}$ & $Q 1$ & $Q_{\mathrm{i}}$ & & & & & \\
\hline Bulgaria & 3,696 & 2,156 & 2,002 & 4,100 & 5,192 & 3,553 & 3,784 & 3,847 & - & 2,509 & 6,117 \\
\hline Czech R. & 4,130 & 2,409 & 2,237 & 3,283 & 4,650 & 3,182 & 3,333 & 3,349 & 3,948 & 2,560 & 4,142 \\
\hline Hungary & 3,695 & 2,155 & 2,001 & 3,189 & 4,660 & 3,189 & 3,189 & 3,411 & 3,280 & 2,577 & 3,639 \\
\hline Poland & 3,721 & 2,170 & 2,015 & 3,522 & - & - & 3,387 & - & - & 3,188 & - \\
\hline Romania & 3,273 & 1,909 & 1,773 & 3,395 & 4,455 & 3,048 & 3,171 & 3,226 & 3,325 & 2,638 & 3,659 \\
\hline Slovakia & 4,168 & 2,431 & 2,258 & 3,635 & 4,953 & 3,389 & 3,407 & 4,937 & 3,702 & 2,811 & 3,795 \\
\hline
\end{tabular}

Infliximab biosimilar as first-line and second-line treatment

Monitoring and administration costs were estimated according to clinical guidelines. Tariffs from the National Health Insurance Fund Administrations (NHIFA) were used to assess monitoring (outpatient visits, lab tests, imaging) and administration (visits to nurse, outpatients visit) costs. In the case of unavailable price data in a country, Hungarian tariffs were converted to estimate these costs.

\section{Assumptions in model}

\section{Movements between model states}

Based on the results of a previous review [11], we assumed that the 3-month discontinuation probability is $0.049 \%$ for all treatments. The probabilities that a given biological drug will be selected as second-line treatment are presented in Table 1. These rates were derived from the Hungarian NHIFA database [10] and were applied to each of the six countries.
We assumed that in $65 \%$ of the cases when originator infliximab would have been selected as a first-line or second-line treatment, the physician would prescribe biosimilar infliximab. Also, an assumption was made that in $25 \%$ of the cases when a non-infliximab tumour necrosis factor inhibitor (TNF-inhibitor, namely adalimumab, certolizumab, etanercept and golimumab) would have been selected as a first-line or second-line treatment, the physician would prescribe biosimilar infliximab (linearly reaching these percentages until the end of the first year, and remaining until the end of the third year).

\section{Interchanging}

The rate of interchanging originator infliximab treatment with biosimilar infliximab treatment is $0 \%$ in BSc1 and $80 \%$ in BSc2 (linearly reaching $80 \%$ until the end of the first year, and remaining until the end of the third year). BSc1, when interchangeability is not allowed at all, is the 
Table 4 Results of the scenario analyses

\begin{tabular}{|c|c|c|c|c|c|c|c|}
\hline & \multicolumn{4}{|c|}{ Budget impact (€) } & \multicolumn{3}{|c|}{$\begin{array}{l}\text { Number of new RA patients on biological treatment if } \\
\text { budget savings would be spent on biosimilar infliximab }\end{array}$} \\
\hline & Year 1 & Year 2 & Year 3 & Total & Year 1 & Year 2 & Year 3 \\
\hline Biosimilar scenario 1 & $-945,241$ & $-4,782,462$ & $-9,612,331$ & $-15,340,034$ & 165 & 672 & 1,205 \\
\hline Biosimilar scenario 2 & $-2,394,545$ & $-6,968,620$ & $-11,463,059$ & $-20,826,224$ & 242 & 1,002 & 1,790 \\
\hline
\end{tabular}

Biosimilar scenario1: interchanging of biosimilar and original biologicals is not allowed

Biosimilar scenario2: interchanging of biosimilar and original biologicals is allowed at least 6 months after treatment start

strictest possible option, while $\mathrm{BSc} 2$ is a potential extreme case, with $80 \%$ replacement of originator by biosimilar (e.g., in an extreme situation where the payer would oblige providers to replace the originator treatment).

\section{Sensitivity analysis}

One-way sensitivity analysis was performed by changing different parameters of the model by $\pm 10 \%$ : the assumption on the acquisition cost of biosimilar infliximab, the size of the initial population and its growth rate over time, the discontinuation rates of biological drugs, and the rate of interchanging infliximab with biosimilar infliximab.

\section{Results}

Results of the analysis are presented in Table 4. In 2013, approximately 17,300 RA patients were treated with biological drugs in the six CEE countries. Findings show that in BSc1 the introduction of biosimilar infliximab in the biologic treatment setting led to a total savings of $€ 15.3 \mathrm{M}$ in the first 3 years of its introduction. Allowing for interchanging original infliximab with biosimilar infliximab had a significant impact on budget savings. In $\mathrm{BSc} 2$, the total saving was estimated to be $€ 20.8 \mathrm{M}$ over the 3 years.

The cost savings may be reinvested to treat more patients with biological drugs. If all budget savings were spent on reimbursing biological therapy of new patients with biosimilar infliximab, an additional 1,205 patients in $\mathrm{BSc} 1$ or 1,790 patients in $\mathrm{BSc} 2$ could be treated with biological drugs after 3 years. According to the results of the sensitivity analysis, the number of the initial population treated with biological agents and the assumption on the acquisition cost of the biosimilar were the two main cost drivers (20.1 and $18.6 \%$ ) in the model (Fig. 1).

\section{Discussion}

This is the first study to attempt to estimate the budget impact of introducing the first biosimilar mAb (infliximab) in the CEE countries. The analysis was carried out with multiple scenarios in order to evaluate various assumptions.

Our analysis shows that introducing biosimilar infliximab as a treatment for RA might result in considerable budget savings. We demonstrated that the potential budget savings for the six countries are $€ 0.9, € 4.8$ and $€ 15.3$ million in the first, second and third year of implementation in the strictest scenario (Bsc1), where the interchange from originator infliximab to biosimilar infliximab is not allowed.

Allowing for the interchange from original infliximab to biosimilar infliximab (BSc2) resulted in even more savings compared to the no-interchanging scenario (BSc1). This increase was driven by a faster reduction of patient number on the more expensive originator infliximab. The one-way sensitivity analysis revealed that it was the acquisition price of biosimilar infliximab that had the greatest impact on budget savings. In contrast, the yearly growth rate of the total number of patients treated with biological agents had only a minor effect.

If the budget savings were reinvested in the treatment of additional patients with biosimilar infliximab, 1,205 and 1,790 additional RA patients could be treated in the two BScs, respectively. Thus, the implementation of biosimilar treatment may significantly improve access to biological therapy in the CEE countries. As mentioned in the introduction, the utilization of biological drugs is significantly lower in the CEE countries compared to high-income countries [2]. For example, in the review by Laires et al. [2], the average access rate to biological treatment amongst RA patients was an average of $19.1 \%$ in 15 Western and Southern European countries. In contrast, according to our estimations, the average access rate in the six CEE countries was about $5.3 \%$. Therefore, additional access to biologicals in these countries is particularly precious.

In recently published reviews [4, 5], two budget impact analyses [6, 7] were identified in RA. Budget impacts calculated in our study can hardly be compared directly with the findings of these analyses of biological treatments, due to differences in settings and jurisdictions. However, comparison of relevant findings and conclusions might be 


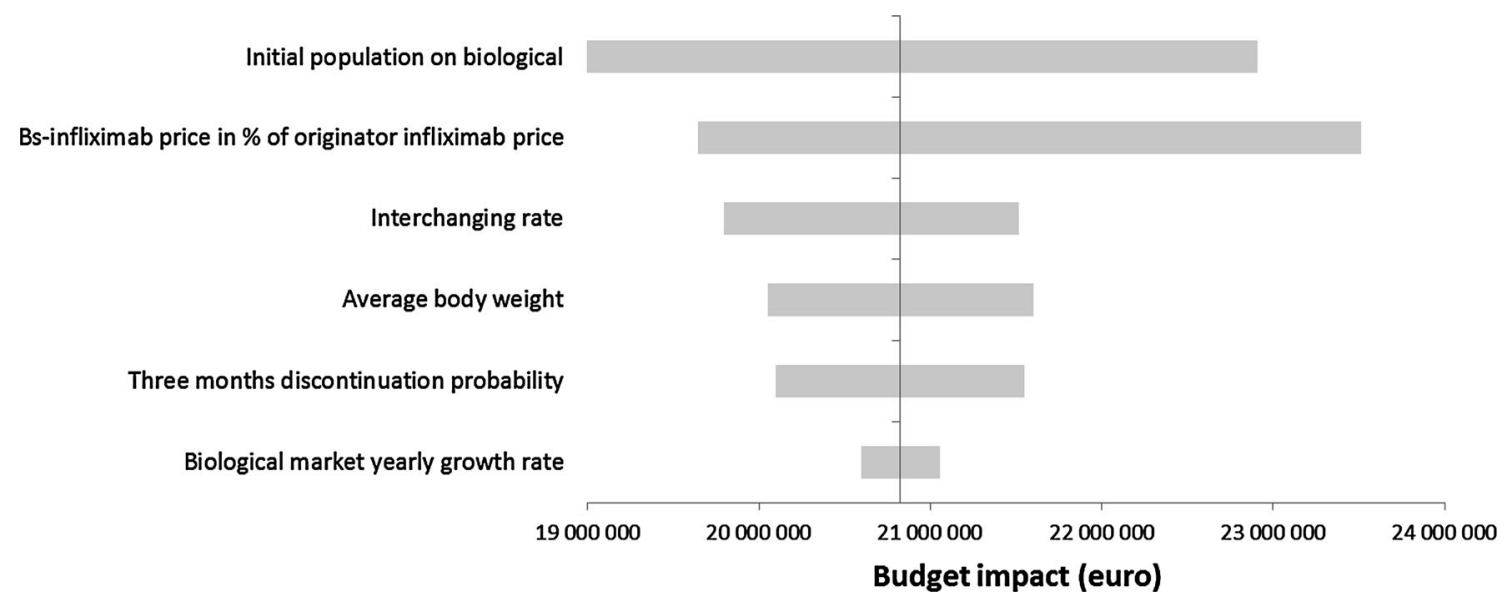

Fig. 1 One-way sensitivity analysis results. Variables included in the one-way sensitivity analysis are listed on the vertical axis. The bars represent the budget impacts with the lowest and highest values of the

meaningful. Launois et al. [6] studied the budget impact initiated by the introduction of rituximab after failure of a TNF-inhibitor therapy from the perspective of the French health care system. They estimated a total savings of $€ 88 \mathrm{M}(23 \%)$ over 4 years, deriving mainly from lower drug costs. The yearly acquisition cost of rituximab was $57 \%$ of the average acquisition costs of TNF-inhibitors. In comparison, in our model, the yearly acquisition cost of biosimilar infliximab was assumed to be $75 \%$ of the originator costs. In both analyses, budget savings were most sensitive to the changes in drug acquisition costs. Both studies similarly conclude that the implementation of biological agents with lower prices might lead to notable cost savings. In an earlier (2002) study by Sørensen and colleagues, the implementation of etanercept and infliximab in the Danish health care system was analysed. The setting of this study was considerably different from ours. The reference case was csDMARD therapy, which might result in significantly higher incremental costs than in our reference case. Sørensen and colleagues reported a $€ 113 \mathrm{M}$ and a $€ 321 \mathrm{M}$ budget increase over 3 years, assuming a modest or a progressive market growth. They highlighted the financial challenges that these new treatment regimens will pose on healthcare systems when they are introduced.

\section{Limitations}

Due to the number of limitations of this BIA, the results should be interpreted with caution. First, it should be taken into account that any model is a simplification of the real treatment process. The model collected only resource use and costs for an average patient, and did not consider other factors such as disease severity, patient characteristics or other disease-related factors. The model did not account for given variable. The variables are ordered so that the widest budget impact interval appears at the top of the figure, the next largest appears second from the top, and so on

the changes in indirect societal costs arising from absence from work. Another limitation is that a dynamic cohort approach was applied in the study, since in each model cycle, some patients left the model while new patients entered it. Yet, we were interested in the total budget impact for the whole population rather than in the individual patient patterns. Also, the model did not account for the potential decrease in future drug costs (neither for biosimilar nor originator). However, it is possible that drug prices will decrease in the future due to increased market competition and the increased number of patients treated with biological agents. This might also lead to budget savings.

Furthermore, the sensitivity analysis showed that the results are highly sensitive to changes in model parameters. Several assumptions were made regarding the practice of available biological therapies based on data available from previous literature or from registers (e.g., discontinuation, switch). Since these data are not always available or reliable for every CEE country, we made a great simplification that discontinuation rates and probabilities of taking up a given treatment are equal in each of the six countries.

Our assumptions about the future use of biosimilar infliximab (market share, interchanging or switching of biological therapies of the current biological) are even more uncertain due to the lack of empirical data on the use and experience with biosimilar treatments (interchangeability, market growth). However, these parameters were tested in the sensitivity analysis.

\section{Conclusions}

Based on the present analysis, the introduction of biosimilar infliximab as an alternative treatment option for RA in 
CEE is predicted to bring substantial cost savings to the national health care budget. The main drivers of budget savings were the current population treated with biological agent and the price of the new drug. Allowing interchange between biosimilar and originator biological drug might have substantial favourable effect on budget savings. Based on these results, the use of biosimilar infliximab appears to be economically attractive, because it offers the potential to reduce the total expenditures or to increase the number of patients treated with biologicals.

Acknowledgments The study was supported by an unrestricted grant from EGIS Pharmaceuticals and Center for Public Affairs Studies Foundation.

\section{References}

1. Sokka, T., Kautiainen, H., Pincus, T., Verstappen, S.M., Aggarwal, A., Alten, R., Andersone, D., Badsha, H., Baecklund, E., Belmonte, M., Craig-Muller, J., da Mota, L.M., Dimic, A., Fathi, N.A., Ferraccioli, G., Fukuda, W., Geher, P., Gogus, F., HajjajHassouni, N., Hamoud, H., Haugeberg, G., Henrohn, D., HorslevPetersen, K., Ionescu, R., Karateew, D., Kuuse, R., Laurindo, I.M., Lazovskis, J., Luukkainen, R., Mofti, A., Murphy, E., Nakajima, A., Oyoo, O., Pandya, S.C., Pohl, C., Predeteanu, D., Rexhepi, M., Rexhepi, S., Sharma, B., Shono, E., Sibilia, J., Sierakowski, S., Skopouli, F.N., Stropuviene, S., Toloza, S., Valter, I., Woolf, A., Yamanaka, H.: Work disability remains a major problem in rheumatoid arthritis in the 2000s: data from 32 countries in the QUEST-RA study. Arthritis Res. Ther. 12(2), R42 (2010). doi:10.1186/ar2951

2. Laires, P.A., Exposto, F., Mesquita, R., Martins, A.P., CunhaMiranda, L., Fonseca, J.E.: Patients' access to biologics in rheumatoid arthritis: a comparison between Portugal and other European countries. Eur. J. Health Econ. 14(6), 875-885 (2013). doi:10.1007/s10198-012-0432-5
3. Mauskopf, J.A., Sullivan, S.D., Annemans, L., Caro, J., Mullins, C.D., Nuijten, M., Orlewska, E., Watkins, J., Trueman, P.: Principles of good practice for budget impact analysis: report of the ISPOR Task Force on good research practices-budget impact analysis. Value Health 10(5), 336-347 (2007)

4. Orlewska, E., Gulacsi, L.: Budget-impact analyses: a critical review of published studies. PharmacoEconomics 27(10), 807-827 (2009)

5. van de Vooren, K., Duranti, S., Curto, A., Garattini, L.: A critical systematic review of budget impact analyses on drugs in the EU countries. Appl. Health Econ. Health Policy 12(1), 33-40 (2014). doi:10.1007/s40258-013-0064-7

6. Launois, R., Payet, S., Saidenberg-Kermanac'h, N., Francesconi, C., Franca, L.R., Boissier, M.C.: Budget impact model of rituximab after failure of one or more TNFalpha inhibitor therapies in the treatment of rheumatoid arthritis. Joint Bone Spine $\mathbf{7 5}(6)$, 688-695 (2008). doi:10.1016/j.jbspin.2008.04.012

7. Sorensen, J., Andersen, L.S.: The case of tumour necrosis factoralpha inhibitors in the treatment of rheumatoid arthritis: a budget impact analysis. PharmacoEconomics 23(3), 289-298 (2005)

8. Tóthfalusi, L., Endrényi, L., Chow, S.-C.: Statistical and regulatory considerations in assessments of interchangeability of biological drug products. Eur. J. Health Econ. (2014). doi:10. 1007/s10198-014-0589-1

9. Péntek, M., Poór, G., Wiland, P., Martina, O., Brzosko, M., Codrenau, C., Brodszky, N., Gulácsi, L.: Biological therapy in inflammatory rheumatic diseases: issues in Central and Eastern European countries. Eur. J. Health Econ. (2014). doi:10.1007/ s10198-014-0592-6

10. Laki, J., Székelyné Mónok, G.: Biological treatments-analysis by the NHIFA. http://www.oep.hu/pls/portal/url/ITEM/ C97D04DF65C8B4CEE040A8C0CB324B94. (2012)

11. Koncz, T., Pentek, M., Brodszky, V., Érsek, K., Orlevska, E., Gulacsi, L.: Adherence to biologic DMARD therapies in rheumatoid arthritis. Expert Opin. Biol. Ther. 9, 1367-1378 (2010)

12. Laki, J., Monok, G., Palosi, M., Gajdacsi, J.Z.: Economical aspect of biological therapy in inflammatory conditions in Hungary. Expert Opin. Biol. Ther. 13(3), 327-337 (2013). doi:10.1517/ 14712598.2013.735654 